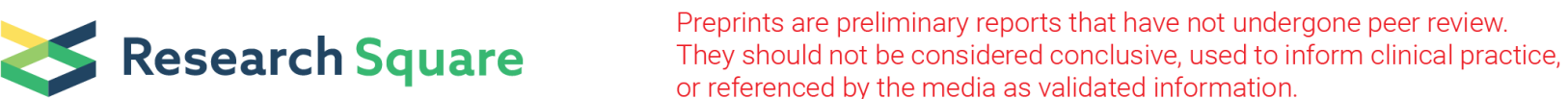

\section{Osimertinib versus afatinib in patients with T790M- positive, non-small-cell lung cancer and multiple central nervous system metastases after failure of initial EGFR-TKI treatment}

\section{Wenli Chen}

The First Affiliated Hospital, Sun Yat-sen University

\section{Xiaoxiao Hua}

The Guanghua School of Stomatology, Hospital of Stomatology, Sun Yat-sen University

\section{Weiguang Yu}

The First Affiliated Hospital, Sun Yat-sen University

Jun Liu

The First Affiliated Hospital, Sun Yat-sen University

\section{Li Xiao}

The Central Hospital of Wuhan, Tongji Medical College, Huazhong University of Science and Technology Guowei Han ( $\sim$ hanson9797@163.com )

Sun Yat-sen University

\section{Research article}

Keywords: Osimertinib, Afatinib, Non-small-cell lung cancer, Central nervous system, Metastases, Survival

Posted Date: October 2nd, 2019

DOI: https://doi.org/10.21203/rs.2.15588/v1

License: (c) (i) This work is licensed under a Creative Commons Attribution 4.0 International License.

Read Full License 


\section{Abstract}

Background The purpose of this study was to compare the efficacy of osimertinib (OSI) versus afatinib (AFA) in patients with T790M-positive, non-small-cell lung cancer (NSCLC) and multiple central nervous system (CNS) metastases after failure of initial epidermal growth factor receptor tyrosine kinase inhibitor (EGFR-TKI) treatment. Methods The cohort consisting of 124 patients (OSI: $n=60$, median age $=64.24$ years [range, 51.91 to 76.57]; AFA: $n=64$, median age $=64.13$ years [range, 50.41 to 77.85 ]) with T790Mpositive NSCLC and multiple CNS metastases after failure of initial EGFR-TKI treatment were consecutively identified at the Cancer Medical Center, Sun Yat-Sen University between March 2017 and July 2017; patients underwent either oral OSI ( $80 \mathrm{mg} /$ day) or oral AFA (40 mg/day) until the occurrence of disease progression, intolerable adverse events (AEs), or death. The co-primary endpoints were overall survival (OS) and progression-free survival (PFS). Results After a median follow-up of 24 months (range, 6 to 26), a significant improvement in OS was observed in the OSI group compared with the AFA group (hazard ratio [HR] 0.30, 95\% confidence interval [Cl] $0.23-0.41 ; p=0.009$; median, 13.0 versus 9.2 months). The median duration of PFS was significantly longer with OSI than with AFA (HR $0.25,95 \% \mathrm{Cl}$ $0.11-0.34 ; p=0.001$; median, 5.4 versus 4.3 months). The proportion of grade 3 or higher AEs was lower with OSI (22.4\%) than with AFA (39.4\%). Conclusion In patients with T790M-positive NSCLC and multiple CNS metastases after failure of initial EGFR-TKI treatment, OSI was associated with significantly improved survival benefit compared with AFA, and OSI exhibited a controllable tolerability profile.

\section{Background}

Patients with activated epidermal growth factor receptor (EGFR) mutation-positive, advanced nonsmall-cell lung cancer (NSCLC) are at increased risk for developing acquired resistance from the p.Thr790Met point (T790M) mutation in EGFR; this often occurs 9-13 months after first- and secondgeneration EGFR tyrosine kinase inhibitors (TKIs) treatment initiation and has an incidence of greater than $50 \%[1-4]$. Central nervous system (CNS) metastases due to disease progression are frequent in these patients with advanced NSCLC harbouring EGFR-TKI-sensitizing mutations[4, 5]. Poor binding of previous EGFR-TKIs to the ATP-binding pocket of EGFR is triggered by the T790M variant, potentially resulting in disease progression[6, 7].

Osimertinib (OSI; TAGRISSO, AstraZeneca), an oral, 3rd-generation, irreversible EGFR-TKI that selectively inhibits both EGFR-TKI-sensitizing and EGFR T790M resistance mutations, has been approved by the Food and Drug Administration (FDA) on November 13, 2015 to treat patients with acquired EGFR T790M resistance or progression on or after EGFR-TKI therapy, and it may resolve the impasse[8, 9]. Data from previous trials indicated that OSI efficacy in the EGFR-mutated NSCLC cohort with T790M mutation was superior to that of first- or second-generation EGFR-TKIs, with a similar safety profile and lower rates of serious adverse events (AEs)[8]. In a phase I/II clinical trial (AURA Study Phase II Extension Component, NCT01802632)[2] involving 198 evaluable patients with EGFR-TKI-pretreated EGFR- and T790M-positive NSCLC, showed that OSI leads to a promising median progression-free survival (PFS)(12.3 months, 95\% $\mathrm{Cl}, 9.5$ to 13.8), and median durable response (15.2 months, $95 \% \mathrm{Cl}, 11.3$ to not calculable). These 
findings were verified by 2 subsequent Phase II studies involving OSI $(80 \mathrm{mg} / \mathrm{d})$ in 411 individuals with T790M-positive NSCLC, in which the median PFS was 11.0 months[5].

Afatinib (AFA), an irreversible ErbB family blocker, inhibits tyrosine kinase activity of EGFR and pertinent ErbB family dimers $[10,11]$. Single-agent AFA has shown remarkable survival benefits compared with platinum-based chemotherapy in earlier treatment-naïve EGFR-mutated NSCLC[12-15]. It has also exhibited modest clinical activity in those cases who acquired resistance to first- and second-generation EGFR-TKIs and progressed on these drugs following initial benefit[16-18]. After the approval of OSI for T790M-positive NSCLC, the standard of care should be OSI rather than AFA. However, in China, the reasons why AFA is used for so many patients are that compared with OSI, AFA with lower cost is easier to obtain for patients.

Nevertheless, whether OSI has superior survival benefits and higher activity against T790M-positive NSCLC and multiple CNS metastases after failure of initial EGFR-TKI treatment compared with AFA remains unknown[16-19]. Furthermore, prior contradictory data could be clarified, indicating heterogeneous data resulting from the subjects harbouring indeterminate EGFR-mutated subtypes, small sample sizes, confounding terminology, non-targeted therapy, wide confidence intervals ( $\mathrm{Cl}$ ), or dubious statistical power $[1,6]$. We therefore conducted a retrospective review of patients with T790M-positive NSCLC and multiple CNS metastases after failure of initial EGFR-TKI treatment to compare the efficacy of OSI versus AFA therapy. To our knowledge, this is the first analysis that retrospectively compared OSI against AFA for the management for T790M-positive NSCLC and multiple CNS metastases after failure of initial EGFR-TKI treatment in an Asian population.

\section{Methods}

\section{Study design and patients}

Clinical data of individuals with T790M-positive NSCLC and multiple CNS metastases after failure of initial EGFR-TKI treatment from a registry database were identified at the Cancer Medical Centre, Sun YatSen University (CMC; Guangzhou, China) between March 2017 and July 2017. Information regarding OSI or AFA delivery, tumour EGFR mutation status, and survival were retrieved from medical records. Tumours were assessed every 6 weeks thereafter by CT, X-rays, bone scans, and MRI as indicated. AEs were evaluated in accordance with the US National Cancer Institute's Patient-Reported Outcomes Version of the Common Terminology Criteria for Adverse Events (PRO-CTCAE)[20]. The co-primary endpoints were overall survival (OS) and PFS. Inclusion criteria were defined as: patients aged $\geq 50$ years with a histologically and/or cytologically confirmed NSCLC harbouring a sensitizing EGFR T790M mutation after failure of initial EGFR-TKI treatment; available NSCLC specimens before initial EGFR-TKI treatment; multiple CNS metastases ( $\geq 3$ metastatic lesions) confirmed by imaging evidence (e.g., computed tomography [CT], magnetic resonance imaging [MRI]); patients receiving either oral $80 \mathrm{mg} / \mathrm{d}$ OSI or oral $40 \mathrm{mg} / \mathrm{d}$ AFA until disease progression, intolerable AEs, or death after failure of initial EGFR-TKI treatment[2, 10]; adequate organ function[13]; Eastern Cooperative Oncology Group (ECOG) status of 0-1. 
The main exclusion criteria were: previous chemotherapy, radiotherapy, chemoradiotherapy, or surgery for NSCLC and/or CNS metastases; symptomatic CNS metastases at the initial administration of OSI or AFA; severe digestive diseases affecting drug absorption (e.g., perforation and/or fistula formation); insufficient imaging data; discontinuation or interruption of OSI or AFA; intolerable AEs: (e.g., uncontrolled diabetes or hypertension) that have a significant impact on the co-primary endpoints; severe infection (e.g., HIV infection).

We included a total of 172 patients with T790M-positive NSCLC and multiple CNS metastases after failure of initial EGFR-TKI treatment from the retrospective cohort between March 2017 and July 2017. Forty-eight (27.9\%) individuals were excluded on account of the inclusion and exclusion criteria, leaving 124 eligible cases for final analysis, as summarized in Figure 1 (OSI: $n=60$, median age $=64.24$ years [range, 51.91 to 76.57]; AFA: $n=64$, median age $=64.13$ years [range, 50.41 to 77.85 ]). No significant differences were detected in the demographic data between groups, as presented in Table 1.

\section{Statistical analysis}

NSCLC stage was determined according to the Lung Cancer Stage Classification System. Tumour mutation status was tested on plasma or tissue specimens at the State Key Laboratory, Sun Yat-Sen University, as reported[1, 5]. PFS was calculated from the initiation of drug treatment until the date of disease progression according to RECIST 1.1 or death from any cause, whichever occurred first. OS was calculated from the initiation of drug treatment until the date of death. Comparisons of continuous variables between groups were evaluated using Student's t-test or ANOVAs. The Fisher exact test or Pearson $\chi^{2}$ were used for binary categorical variables. Time-to-symptom progression in the subgroup with baseline multiple CNS metastases, median PFS, and median OS were estimated using the Kaplan-Meier methodology. Between-group comparisons for survival probabilities were assessed using the log-rank test. Survival differences were estimated using the Cox proportional hazard regression model in which partial baseline data (e.g., age, smoking status) were adjusted. Missing data were not included in the study, which is consistent with previous descriptions[21]. The hazard ratio (HR) and corresponding 95\% Cls were estimated using Cox proportional hazards models. HRs for PFS and OS were also estimated using a multivariate Cox regression model with adjustment for potential confounding factors. A two-sided $p$ value of $<0.05$ was considered statistically significant. Data were analysed using SPSS, version 24.0 (IBM Corp., Armonk, NY).

\section{Results}

\section{Survival analysis}

The median duration of follow-up was 24 months (range, 6 to 26). At the final follow-up, the median duration of OS was 13.0 months (range, 3.4 to 15.8) in the OSI group and 9.2 months (range, 3.2 to 11.1) in the AFA group. The main cause of death in patients tends to coma induced by CNS metastases. The median duration of OS was significantly longer with OSI than with AFA (HR $0.30 ; 95 \% \mathrm{Cl} 0.23-0.41 ; p=$ 
0.009; Figure 2). The median duration of PFS was 5.4 months (range, 2.4 to 9.2 ) in the OSI group and 4.3 months (range, 2.2 to 7.9 ) in the AFA group. The median duration of PFS was significantly longer among patients undergoing OSI than among those treated with AFA (HR 0.25; 95\% $\mathrm{Cl} 0.11-0.34 ; p=0.001$; Figure 3).

\section{Adverse events}

Safety was assessed for each patient treated with OSI or AFA. AEs occurred in 48 of 60 patients (80.0\%) in the OSI group and in 59 of $64(92.2 \%)$ in the AFA group. Drug-related AEs are summarized in Table 2. The proportion of grade 3 or higher AEs was lower with OSI (22.4\%) than with AFA (39.4\%). Most AEs were mild-to-moderate in severity and reversible. In our study, there was not significant difference in the hematological toxicity between groups, although it is one of the major side effects of EGFR-TKI.

The OSI-related AEs that were most commonly reported included diarrhoea (24 patients [28.2\%]; 8 [9.4\%] were deemed as $\geq$ grade 3), rash (in 22 [25.9\%]; 5 [5.9\%] were $\geq$ grade 3), dry skin (in 18 [21.2\%]; 6 [7.1\%] were deemed as $\geq$ grade 3 ), and paronychia (in 11 [12.9\%]; no one was deemed as $\geq$ grade 3 ). Most rashes were regarded as grade 1 or $2(17$ [20.0\%] vs. 11 [10.1\%] in the OSI and AFA groups, respectively; $p$ $=0.05$ ). The most common AFA-related AEs were diarrhoea (47 patients [43.1\%]; 25 [22.9\%] were deemed as $\geq$ grade 3), alopecia (in 15 [13.8\%]; 6 [5.5\%] were $\geq$ grade 3), asthenia (in 6 [5.5\%]; no one was deemed as $\geq$ grade 3 ), decreased appetite (in 5 [4.6\%]; no one was deemed as $\geq$ grade 3 ) and rash (in 18 [16.5\%]; 7 [6.4\%] were deemed as $\geq$ grade 3 ). OSI was associated with a lower rate of AEs leading to dose reductions than was AFA (in $6[7 \%]$ and $16[10 \%]$, respectively, $p=0.02$ ).

\section{Discussion}

Findings from our retrospective analysis comparing the efficacy of OSI versus AFA in patients with T790M-positive NSCLC and multiple CNS metastases after failure of initial EGFR-TKI treatment, showed that despite the short follow-up time, our finding confirmed similar results from prior reports[1,22] with the same treatment regimen associated; we observed improved outcomes for patients with T790M-positive NSCLC and multiple CNS metastases, including similar survival benefit from OSI for such cohort. However, the shorter survival was detected in our study compared some previous studies[2, 6, 8]. The underlying background and reason of the shorter survival could be the fact that patients with T790Mpositive NSCLC and multiple CNS metastases tend to have a worse prognosis than those who have no such metastases.

Previous reports of OSI or AFA in T790M-positive NSCLC have encountered unexpected obstacles, including non-uniform definitions of variables, undefined CNS metastases, and incoherent treatment regimens, which may lead to survival variability among patient reports[1, 2, 23-25]. Although the limited sample size makes it difficult to reach convincing conclusions in the current analysis, the survival advantage of OSI is more significant compared with that of AFA, but further validation of our findings is required. The key limiting factor for such cohort is to grasp the timing of multiple CNS metastases. For PFS, a well-defined finding favouring the OSI regimen was described[2, 25], although PFS was not the 
primary endpoint. The reason why PFS but not OS was affected could be associated with small cohort of research subjects with NSCLC progression who failed to undertake EGFR-TKI treatment.

A population-based study involving 15 medical institutes that cover a population of three million people indicated the disadvantages of pre-treatment before AFA in patients with NSCLC harboring an acquired EGFR T790M mutation[18]. However, the evidence-based trials regarding the optimal regimen in the management of cases with T790M-positive NSCLC and multiple CNS metastases remain controversial[23, 26]. Within this context, evidence has indicated that neither the first-generation nor second-generation EGFR-TKIs distinctly improve the OS among those cases with T790M-positive NSCLC[23, 27]. Nonetheless, whether there were multiple CNS metastases in the studied cohorts and whether CNS metastases offset some of the EGFR-TKI efficacy remain ambiguous[27, 28], which could obscure the facts. There is a significant difference in the composition ratio of patients with multiple CNS metastases in each group, possibly resulting from variability in the response to the EGFR-TKI in diverse reports $[19,29]$. In the present study, the survival benefits of OSI over AFA were consistent with prospective randomized trials[22, 25, 30,31]in which the composition ratio of multiple CNS metastases was assessed in subgroup analyses. Consequently, the between-group differences in survival benefits might be attributed to drug mechanistic differences[22, 32]. Additionally, analogous studies, which compared OSI with AFA in individuals with T790M-positive NSCLC following chemotherapy, also demonstrated similar findings $[15,33,34]$.

However, consensus is lacking as to what is the optimal treatment regimen for such cohorts[5, 32, 35]. At present, patients with progressing NSCLC who received first- or second-generation EGFR-TKIs are best treated with OSI alone or in combination with chemotherapy, if possible[2, 5, 7]. Although OSI is not part of the current standard of care in China, it was approved by the FDA for the management of the T790Mpositive NSCLC patients[22,36]. Previous studies of cases with T790M-positive NSCLC have confirmed that the irreversible inhibitor OSI offers more survival benefits compared with other reversible EGFRTKIs[4, 7]. Of note, those studies in which some subjects failed to be included based on the T790M mutation appear to have unclear data or to have restricted subjects according to the researcher's preference. Additionally, OSI has been less frequently used because the empirical use of drugs is common in clinical practice despite the lack of reliable supportive evidence in the first few years[2, 22, 27].

Although our analysis contributes to gaining a better understanding of the survival benefits of the continued OSI treatment in the setting of T790M-positive NSCLC and multiple CNS metastases after failure of initial EGFR-TKI treatment, there are certain limitations to discuss. First, the level of evidence in the current study is limited due to the weaknesses inherent in a retrospective analysis including treatments, follow-up, and missing data. A number of cases were excluded at the final follow-up owing to imperfect follow-up data, which may introduce bias. Although the capacity to draw reliable conclusions may be reduced due to the biases that may have contributed to differences in outcomes, it is almost impossible for these issues to play a crucial role due to the baseline data and the contemporaneous methods following widespread standards. However, prospective studies are required to verify the survival 
benefit of OSI over AFA. Second, the current outcomes were limited by our follow-up protocol (i.e. frequency, length). Third, possible heterogeneity seems hard to avoid, even though considerable variables have been adjusted.

\section{Conclusions}

Our study demonstrated that a noteworthy survival superiority of OSI over AFA was observed in patients with T790M-positive NSCLC and multiple CNS metastases after failure of initial EGFR-TKI treatment. The survival benefits with OSI might reflect its broader mechanism of action compared with AFA. We believe that OSI could be a more effective therapeutic option than AFA in the current setting. Although our analysis was powered to assess end-points, given the high mortality associated with T790M-positive NSCLC, if OSI or AFA were to be re-evaluated in a comparable setting, extended follow-up time is needed to determine whether our findings are confirmed over an extended follow-up period.

\section{Abbreviations}

OSI: osimertinib; AFA: afatinib; NSCLC: non-small-cell lung cancer; EGFR-TKl: epidermal growth factor receptor tyrosine kinase inhibitor; AEs: adverse events; OS: overall survival; PFS: progression-free survival; SD: standard deviation; Cl: confidence interval; IQR: interquartile range; HR: hazard ratio; T790M:

p.Thr790Met; CT: computed tomography; MRI: magnetic resonance imaging; ECOG: Eastern Cooperative Oncology Group; VCl: vascular cognitive impairment; RECIST: Response Evaluation Criteria in Solid Tumours.

\section{Declarations}

\section{Acknowledgements}

The authors would like to thank Lei Cao for assistance in retrieving patients' medical records and radiographs.

\section{Funding}

This work was supported by grants from the National Natural Science Foundation of China (31430031). The funding agency did not play a role in the study design, analysis and interpretation of the data, or the writing of the manuscript.

\section{Availability of data and materials}

The datasets used and/or analysed during the current study are available from the corresponding author upon reasonable request.

\section{Authors' contributions}


YJ: Planning and study design, study execution, and writing-initial draft. XH: Statistical analysis/interpretation, and writing-final revision. JL, LX, and DL: Planning and study design. NS: Data collection and study execution. NS, MZ and GH: Writing-initial draft, and writing-final revision. All authors were involved in the manuscript preparation and approved the submitted version.

\section{Ethics approval and consent to participate}

This retrospective study was approved by the Institutional Review Board and Ethics Review Board of The First Affiliated Hospital, Sun Yat-sen University (No. 2014594). Patients' informed consent was waived by the Ethics Review Boards.

\section{Consent for publication}

Not applicable.

\section{Competing interests}

The authors declare that there is no conflict of interest.

\section{Tables}

Table 1. Baseline characteristics of patient groups

\begin{tabular}{llll}
\hline Variable & OSI $(\mathrm{n}=60)$ & $\mathrm{AFA}(\mathrm{n}=64)$ & $p$ - value \\
\hline Age $($ years $)$ & $64.24 \pm 12.33$ & $64.13 \pm 13.72$ & $0.72^{\mathrm{a}}$ \\
\hline Sex $($ male $/$ female $)$ & $25 / 35$ & $28 / 36$ & $0.82^{\mathrm{b}}$ \\
\hline BMI $\left(\mathrm{kg} / \mathrm{m}^{2}\right)$ & $23.74 \pm 2.31$ & $24.15 \pm 2.46$ & $0.26^{\mathrm{a}}$ \\
\hline Smoking status & & & $0.81^{\mathrm{c}}$ \\
\hline$\quad$ Never a smoker & 11 & 13 & \\
\hline Former smokers & 32 & 30 & \\
\hline$\quad$ Current smokers & 17 & 21 & \\
\hline Time from diagnosis of NSCLC (months) & & & $0.78^{\mathrm{c}}$ \\
$<6$ & 15 & 17 & \\
\hline $6-12$ & 35 & 33 & \\
$>12$ & 10 & 14 & \\
\hline Largest size of brain metastasis & & & \\
\hline$\leq 10 \mathrm{~mm}$ & 22 & 18 & \\
\hline$>10 \mathrm{~mm}$ & 38 & 46 & \\
\hline Number of brain metastases & & & \\
\hline$\leq 3$ & 32 & 30 & \\
\hline$>3$ & 28 & 34 & \\
\hline ECOG performance status & & & \\
\hline 0 & 9 & 12 & \\
\hline 1 & 27 & 25 & \\
\hline 2 & 24 & 27 & \\
\hline
\end{tabular}


${ }^{a}$ Analysed using independent-samples t-test. ${ }^{b}$ Analysed using Chi-squared test. ${ }^{c}$ Analysed using the MannWhitney test. BMI: body mass index; OSI: osimertinib; AFA: afatinib; NSCLC: non-small-cell lung cancer; ECOG: Eastern Cooperative Oncology Group.

Table 2. Drug-related adverse events

\begin{tabular}{|c|c|c|c|c|c|c|}
\hline \multirow[t]{2}{*}{ Variable } & \multicolumn{2}{|c|}{$\begin{array}{c}\text { OSI }(\mathrm{n}=85 \text { AEs involving } 48 \\
\text { patients })\end{array}$} & \multicolumn{2}{|c|}{$\begin{array}{c}\mathrm{AFA}(\mathrm{n}=109 \text { AEs involving } 59 \\
\text { patients })\end{array}$} & \multicolumn{2}{|c|}{$p$ - value ${ }^{a}$} \\
\hline & $\begin{array}{c}\text { All grades } \\
(\%)\end{array}$ & $\begin{array}{c}\geq \text { Grade } 3 \\
(\%)\end{array}$ & All grades (\%) & $\geq$ Grade $3(\%)$ & $\begin{array}{c}\text { All grades } \\
(\%)\end{array}$ & $\begin{array}{c}\geq \text { Grade } 3 \\
(\%)\end{array}$ \\
\hline Diarrhoea & $24(28.2)$ & $8(9.4)$ & $47(43.1)$ & $25(22.9)$ & $0.03 *$ & 0.13 \\
\hline Rash & $22(25.9)$ & $5(5.9)$ & $18(16.5)$ & $7(6.4)$ & 0.11 & 0.88 \\
\hline Dry skin & $18(21.2)$ & $6(7.1)$ & $12(11.0)$ & $5(4.6)$ & 0.52 & 0.46 \\
\hline Paronychia & $11(12.9)$ & $0(0.0)$ & $6(5.5)$ & $0(0.0)$ & 0.07 & NA \\
\hline Alopecia & $3(3.5)$ & $0(0.0)$ & $15(13.8)$ & $6(5.5)$ & $0.02 *$ & $0.03^{*}$ \\
\hline Asthenia & $2(2.4)$ & $0(0.0)$ & $6(5.5)$ & $0(0.0)$ & 0.27 & NA \\
\hline Decreased & $5(5.8)$ & $0(0.0)$ & $5(4.6)$ & $0(0.0)$ & 0.69 & NA \\
\hline
\end{tabular}

appetite

*Statistically significant. ${ }^{a}$ Analysed using Chi-squared test. AEs: adverse events; OSI: osimertinib; AFA: afatinib; NA: not applicable.

\section{References}

1. Remon J, Caramella C, Jovelet C, Lacroix L, Lawson A, Smalley S et al. Osimertinib benefit in EGFRmutant NSCLC patients with T790M-mutation detected by circulating tumour DNA. Annals of Oncology. 2017;28(4):784-90.

2. Yang JCH, Ahn MJ, Kim DW, Ramalingam SS, Sequist LV, Su WC et al. Osimertinib in Pretreated T790M-Positive Advanced Non-Small-Cell Lung Cancer: AURA Study Phase II Extension Component. Journal of Clinical Oncology. 2017;35(12):1288-+.

3. Lin CC, Shih JY, Yu CJ, Ho CC, Liao WY, Lee JH et al. Outcomes in patients with non-small-cell lung cancer and acquired Thr790Met mutation treated with osimertinib: a genomic study. Lancet Respiratory Medicine. 2018;6(2):107-16.

4. Reungwetwattana T, Nakagawa K, Cho BC, Cobo M, Cho EK, Bertolini A et al. CNS Response to Osimertinib Versus Standard Epidermal Growth Factor Receptor Tyrosine Kinase Inhibitors in Patients With Untreated EGFR-Mutated Advanced Non-Small-Cell Lung Cancer. Journal of Clinical Oncology. 2018;36(33):3290-+.

5. Goss G, Tsai CM, Shepherd FA, Ahn MJ, Bazhenova L, Crino L et al. CNS response to osimertinib in patients with T790M-positive advanced NSCLC: pooled data from two phase II trials. Annals of Oncology. 2018;29(3):687-93.

6. Mok TS, Wu YL, Ahn MJ, Garassino MC, Kim HR, Ramalingam SS et al. Osimertinib or PlatinumPemetrexed in EGFR T790M-Positive Lung Cancer. New England Journal of Medicine. 2017;376(7):629-40. 
7. Wu YL, Ahn MJ, Garassino MC, Han JY, Katakami N, Kim HR et al. CNS Efficacy of Osimertinib in Patients With T790M-Positive Advanced Non-Small-Cell Lung Cancer: Data From a Randomized Phase III Trial (AURA3). Journal of Clinical Oncology. 2018;36(26):2702-+.

8. Soria JC, Ohe Y, Vansteenkiste J, Reungwetwattana T, Chewaskulyong B, Lee KH et al. Osimertinib in Untreated EGFR-Mutated Advanced Non-Small-Cell Lung Cancer. New England Journal of Medicine. 2018;378(2):113-25.

9. Greig SL. Osimertinib: First Global Approval. Drugs. 2016;76(2):263-73.

10. Paz-Ares L, Tan EH, O'Byrne K, Zhang L, Hirsh V, Boyer M et al. Afatinib versus gefitinib in patients with EGFR mutation-positive advanced non-small-cell lung cancer: overall survival data from the phase IIb LUX-Lung 7 trial. Annals of Oncology. 2017;28(2):270-7.

11. Schuler M, Yang JCH, Park K, Kim JH, Bennouna J, Chen YM et al. Afatinib beyond progression in patients with non-small-cell lung cancer following chemotherapy, erlotinib/gefitinib and afatinib: phase III randomized LUX-Lung 5 trial. Annals of Oncology. 2016;27(3):417-23.

12. Schuler M, Wu YL, Hirsh V, O'Byrne K, Yamamoto N, Mok T et al. First-Line Afatinib versus Chemotherapy in Patients with Non-Small Cell Lung Cancer and Common Epidermal Growth Factor Receptor Gene Mutations and Brain Metastases. Journal of Thoracic Oncology. 2016;11(3):380-90.

13. Park K, Tan EH, O'Byrne K, Zhang L, Boyer M, Mok T et al. Afatinib versus gefitinib as first-line treatment of patients with EGFR mutation-positive non-small-cell lung cancer (LUX-Lung 7): a phase 2B, open-label, randomised controlled trial. Lancet Oncology. 2016;17(5):577-89.

14. Soria JC, Felip E, Cobo M, Lu S, Syrigos K, Lee KH et al. Afatinib versus erlotinib as second-line treatment of patients with advanced squamous cell carcinoma of the lung (LUX-Lung 8): an openlabel randomised controlled phase 3 trial. Lancet Oncology. 2015;16(8):897-907.

15. Yang JCH, Wu YL, Schuler M, Sebastian M, Popat S, Yamamoto $N$ et al. Afatinib versus cisplatinbased chemotherapy for EGFR mutation-positive lung adenocarcinoma (LUX-Lung 3 and LUX-Lung 6): analysis of overall survival data from two randomised, phase 3 trials. Lancet Oncology. 2015;16(2):141-51.

16. Janjigian YY, Smit EF, Groen HJM, Horn L, Gettinger S, Camidge DR et al. Dual Inhibition of EGFR with Afatinib and Cetuximab in Kinase Inhibitor-Resistant EGFR-Mutant Lung Cancer with and without T790M Mutations. Cancer Discovery. 2014;4(9):1036-45.

17. Yoon BW, Kim JH, Lee SH, Choi CM, Rho JK, Yoon S et al. Comparison of T790M Acquisition Between Patients Treated with Afatinib and Gefitinib as First-Line Therapy: Retrospective Propensity Score Matching Analysis. Translational Oncology. 2019;12(6):852-8.

18. Miyazaki K, Tamura T, Kaburagi T, Saito K, Inagaki M, Yamashita T et al. Real Clinical Practice of Using Afatinib Therapy in NSCLC Patients with an Acquired EGFR T790M Mutation. Anticancer Research. 2018;38(9):5409-15.

19. van Kempen LC, Wang HJ, Aguirre ML, Spatz A, Kasymjanova G, Vilacha JF et al. Afatinib in Osimertinib-Resistant EGFR ex19del/T790M/P794L Mutated NSCLC. Journal of Thoracic Oncology. 2018;13(9):E161-E3. 
20. Dueck AC, Mendoza TR, Mitchell SA, Reeve BB, Castro KM, Rogak LJ et al. Validity and Reliability of the US National Cancer Institute's Patient-Reported Outcomes Version of the Common Terminology Criteria for Adverse Events (PRO-CTCAE). Jama Oncology. 2015;1(8):1051-9.

21. Fang WF, Huang YH, Hong SD, Zhang ZH, Wang MH, Gan JD et al. EGFR exon 20 insertion mutations and response to osimertinib in non-small-cell lung cancer. Bmc Cancer. 2019;19.

22. Ramalingam SS, Yang JCH, Lee CK, Kurata T, Kim DW, John T et al. Osimertinib As First-Line Treatment of EGFR Mutation-Positive Advanced Non-Small-Cell Lung Cancer. Journal of Clinical Oncology. 2018;36(9):841-+.

23. Camidge DR, Janne PA, Sequist LV, Chand V, Dowling E, Gu Y et al. A PHASE IB STUDY OF HIGHDOSE INTERMITTENT (HDI) AFATINIB IN EGFR T790M MUTATION-POSITIVE NON-SMALL CELL LUNG CANCER PATIENTS WITH ACQUIRED RESISTANCE TO REVERSIBLE EGFR TKIS. Journal of Thoracic Oncology. 2013;8:S893-S.

24. Zhang SR, Zheng XL, Huang HX, Wu K, Wang B, Chen XF et al. Afatinib increases sensitivity to radiation in non-small cell lung cancer cells with acquired EGFR T790M mutation. Oncotarget. 2015;6(8):5832-45.

25. Ballard P, Yates JWT, Yang ZF, Kim DW, Yang JCH, Cantarini M et al. Preclinical Comparison of Osimertinib with Other EGFR-TKIs in EGFR-Mutant NSCLC Brain Metastases Models, and Early Evidence of Clinical Brain Metastases Activity. Clinical Cancer Research. 2016;22(20):5130-40.

26. Lin YT, Chen JS, Liao WY, Ho CC, Hsu CL, Yang CY et al. Clinical outcomes and secondary epidermal growth factor receptor (EGFR) T790M mutation among first-line gefitinib, erlotinib and afatinibtreated non-small cell lung cancer patients with activating EGFR mutations. International Journal of Cancer. 2019;144(11):2887-96.

27. Hochmair M, Schwab S, Burghuber O, Koger R, Setinek U, Cseh A et al. Prevalence of EGFR T790M Mutation in NSCLC Patients after Afatinib Failure, and Subsequent Response to Osimertinib. Journal of Thoracic Oncology. 2017;12(11):S2136-S.

28. Oda N, Hotta K, Ninomiya K, Minami D, Ichihara E, Murakami T et al. A phase II trial of EGFR-TKI readministration with afatinib in advanced non-small-cell lung cancer harboring a sensitive nonT790M EGFR mutation: Okayama Lung Cancer Study Group trial 1403. Cancer Chemotherapy and Pharmacology. 2018;82(6):1031-8.

29. Lee K, Kim Y, Jung HA, Lee SH, Ahn JS, Ahn MJ et al. Repeat biopsy procedures and T790M rates after afatinib, gefitinib, or erlotinib therapy in patients with lung cancer. Lung Cancer. 2019;130:87-92.

30. Remon J, Menis J, Hasan B, Peric A, De Maio E, Novello S et al. The APPLE Trial: Feasibility and Activity of AZD9291 (Osimertinib) Treatment on Positive PLasma T790M in EGFR-mutant NSCLC Patients. EORTC 1613. Clinical Lung Cancer. 2017;18(5):583-8.

31. Ohe $\mathrm{Y}$, Imamura F, Nogami N, Okamoto I, Kurata T, Kato T et al. Osimertinib versus standard-of-care EGFR-TKI as first-line treatment for EGFRm advanced NSCLC: FLAURA Japanese subset. Japanese Journal of Clinical Oncology. 2019;49(1):29-36. 
32. Hochmair MJ, Morabito A, Hao D, Yang CT, Soo RA, Yang JCH et al. Sequential treatment with afatinib and osimertinib in patients with EGFR mutation-positive non-small-cell lung cancer: an observational study. Future Oncology. 2018;14(27):2861-74.

33. Kobayashi K, Naoki K, Kuroda A, Yasuda H, Kawada I, Soejima K et al. EGFR-mutant Non-small Cell Lung Cancer Accompanied by Transient Asymptomatic Pulmonary Opacities Successfully Treated with "Stop-And-Go" Osimertinib. Internal Medicine. 2018;57(7):1007-10.

34. Lee CK, Novello S, Ryden A, Mann H, Mok T. Patient-Reported Symptoms and Impact of Treatment With Osimertinib Versus Chemotherapy in Advanced Non-Small-Cell Lung Cancer: The AURA3 Trial. Journal of Clinical Oncology. 2018;36(18):1853-+.

35. Jiang T, Su CX, Ren SX, Cappuzzo F, Rocco G, Palmer JD et al. A consensus on the role of osimertinib in non-small cell lung cancer from the AME Lung Cancer Collaborative Group. Journal of Thoracic Disease. 2018;10(7):3909-21.

36. Oxnard GR, Thress KS, Alden RS, Lawrance R, Paweletz CP, Cantarini M et al. Association Between Plasma Genotyping and Outcomes of Treatment With Osimertinib (AZD9291) in Advanced NonSmall-Cell Lung Cancer. Journal of Clinical Oncology. 2016;34(28):3375-+.

37. Yi LL, Fan JS, Qian RL, Luo P, Zhang J. Efficacy and safety of osimertinib in treating EGFR-mutated advanced NSCLC: A meta-analysis. International Journal of Cancer. 2019;145(1):284-94.

\section{Figures}


From March 2017 to July 2017, 172 patients with T790M mutation-positive NSCLC and multiple central nervous system metastases after failure of initial EGFR-TKI treatment were identified and received either oral $80 \mathrm{mg} / \mathrm{d}$ OSI or oral $40 \mathrm{mg} / \mathrm{d}$ AFA until disease progression, intolerable AEs, or death

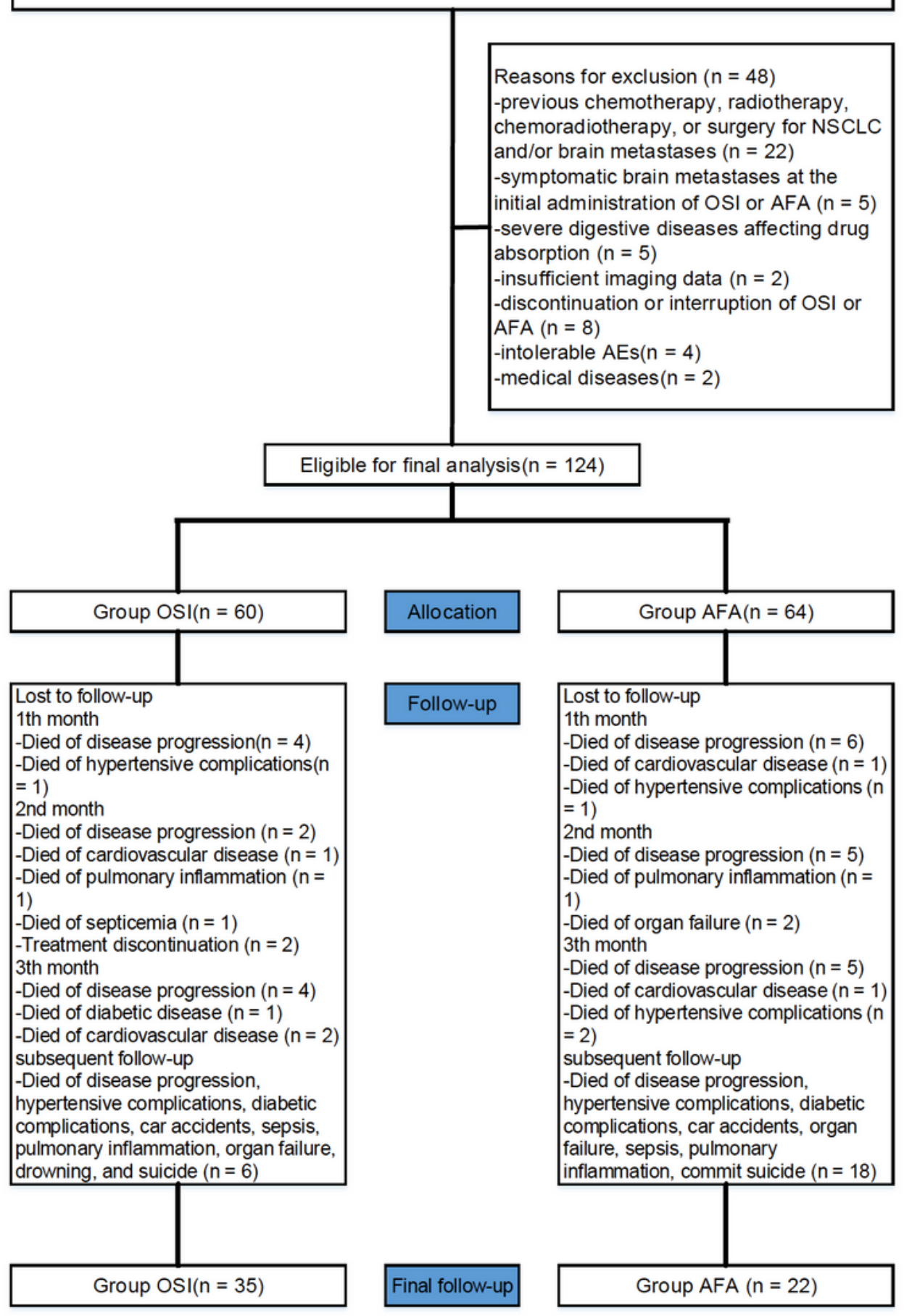

\section{Figure 1}

Flow diagram illustrating the methods used to identify studies to retrospectively compare the efficacy of osimertinib (OSI) versus afatinib (AFA) in patients with T790M-positive, non-small-cell lung cancer (NSCLC) and multiple central nervous system (CNS) metastases after failure of initial epidermal growth factor receptor tyrosine kinase inhibitor (EGFR-TKI) treatment. 


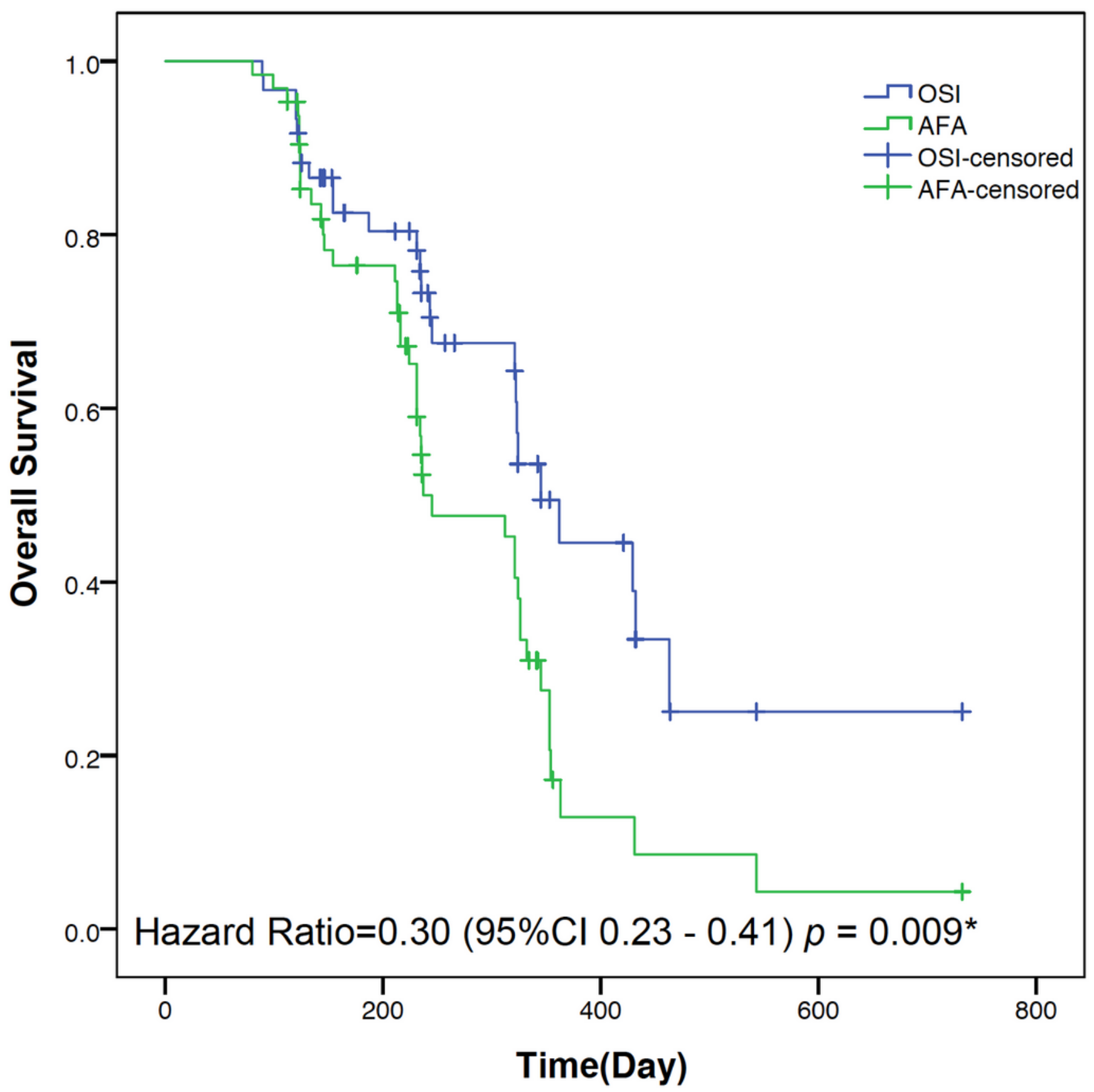

Number at risk

OSI 31

AFA 33

22

26
10

18
6

11
2

5

\section{Figure 2}

Kaplan-Meier curves for OS The median OS was 13.0 months (range, 3.4 to 12.8) for OSI and 9.2 months (range, 3.2 to 10.0) for AFA. A significant difference was observed in the median OS between groups. *HR was calculated using the Cox proportional hazards model, with age, sex and time span of smoking history as covariates and OSI/AFA therapy as the time-dependent factor. With respect to OS, the results were analysed using the log-rank test $(p=0.009)$. 


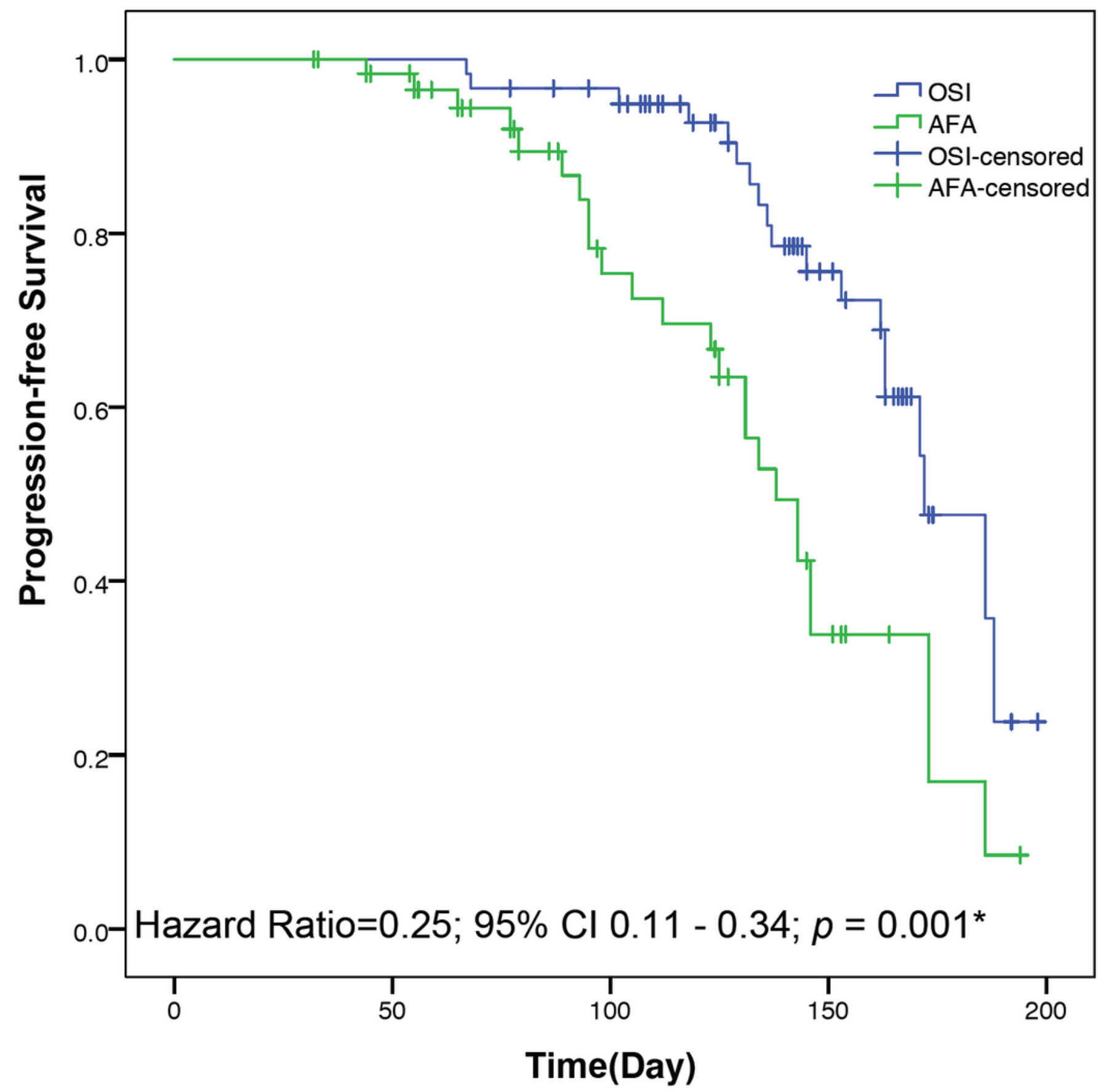

Number at risk

$\begin{array}{llllll}\text { OSI } & 21 & 17 & 8 & 4 & 1 \\ \text { AFA } & 27 & 21 & 12 & 7 & 3\end{array}$

Figure 3

Kaplan-Meier curves for PFS The median PFS was 5.4 months (range, 2.4 to 6.2) for OSI and 4.3 months (range, 2.2 to 4.9) for AFA. A significant difference was detected in the median PFS between groups. *HR was calculated using the Cox proportional hazards model, with age, sex and time span of smoking history as covariates and OSI/AFA therapy as the time-dependent factor. With respect to PFS, the results were analysed using the log-rank test $(p=0.001)$. 